\title{
EL MATRIMONIO ANTE LA FE DEL NOTARIO PÚBLICO
}

\section{Lic. Maria Guadalupe Torres Ramos ${ }^{1}$}

Dr. José Antonio Morales Notario

Abstract: Modern trends require changes in the way marriage is conceived. The Civil Code of the State of Tabasco provides that marriage is an institution in which two persons decide to unite their lives in a common life project. When this is done through a solemn act, it requires to be done before a civil registry officer, with certain formalities. Nevertheless; when the couple decides to end their marital relationship, there is no matter the reason, if there are no assets or children, they can get divorce by the officer of the government who they were married. Otherwise, they must go to a civil court for ruling on the marriage society and the relationship they must conserve with their children. The notary is a legal entity. The States grants public faith to validate certain acts: he is a legal professional who has the responsibility to represent in a notarial instrument, the legality of the acts, read them and explain them to the parties, to provide them with security and legality. In this paper the figure of the notary in Mexico and its importance within the Mexican positive law will be explain, as well as the marriage in presence of a Public Notary also the prenuptial agreement which are currently relevant for those who wish to marry and for society.

Keywords: Marriage, responsibilities, food, Notary Public

\section{Introducción}

En nuestro país, el notariado es una actividad que encuentra sus antecedentes en el Tlacuilo de la época prehispánica. Éste era un funcionario que realizaba la actividad de escriba. Redactaba y relacionaba los hechos y asesoraba a las partes contratantes cuando realizaban alguna operación, pero no eran considerados fedatarios (Pérez Fernández del Castillo, 1983);

\footnotetext{
${ }^{1}$ Egresada de la Maestría en Derecho en la División Académica de Ciencias Sociales y Humanidades de la Universidad Juárez Autónoma de Tabasco en México.

${ }^{2}$ Doctor en Derecho; profesor investigador de tiempo completo en la División Académica de Ciencias Sociales y Humanidades de la Universidad Juárez Autónoma de Tabasco en México.
} 
dejaban constancia de los acontecimientos a través de signos ideográficos y pinturas, con lo que se conservaban los registros (Bañuelos Sánchez, 1976).

Con respecto al matrimonio ante Notario Público, el Papa Alejandro III emitió un decreto en 1170 en el que reconoció la posibilidad de que el matrimonio pudiese celebrar ante Notario, incorporando esta Decretal del Corpus Iuris Canonici. Durante la edad media, las partidas 1265 contenían un modelo de escritura de matrimonio ante escribano público. En el Concilio de Trento, se consideró al Notario como testigo autorizado del matrimonio, aunque no se concretó dicha función. Sin embargo, de los siglos XVI al XIX, algunas minorías religiosas, católicas, protestantes u otras, hicieron uso de los Notarios para contraer matrimonio. En la actualidad, desde 1845 Noruega regula el matrimonio ante notario. Y sólo algunos países como Irán los países del Norte de África lo consideran en sus legislaciones (Zejalbo Martín, 2012).

De igual forma, el matrimonio notarial se comenzó a considerar en Colombia, siendo éste país el pionero en América, ya que la ley colombiana consideró que, si el matrimonio se celebra por la vía religiosa, los contrayentes pueden comparecer ante un juez o notario para solicitar que se les reconozca por el Estado. Otros países como Brasil, Bolivia, Costa Rica y Guatemala también establecen el matrimonio notarial en sus legislaciones. La doctrina considera que, al contar los notarios con la potestad para celebrar matrimonios, se beneficia a los contrayentes pues les permite elegir el lugar de la celebración del matrimonio.

En la actualidad, el Notario Público es un profesional del derecho que cuenta con fe pública otorgada por el Estado, lo que significa que, al momento de circunscribir sus actos a los autorizados por la ley, brinda seguridad y certeza jurídica; además, siempre debe mantener un alto nivel de profesionalismo, total imparcialidad y plena autonomía en sus decisiones, preservando siempre el Estado de derecho. Dentro de sus atributos se encuentra que puede recibir, interpretar, redactar y dar forma legal a la voluntad de quien requiere sus servicios, lo que plasma en un instrumento público y auténtico, elaborado bajo su responsabilidad.

La Ley del Notariado para el Estado de Tabasco lo define como el 
profesional del derecho investido de fe pública para hacer los actos y hechos jurídicos a los que los interesados quieran o deban dar autenticidad conforme a las leyes y autorizado para intervenir en la formación de tales actos o hechos jurídicos, revistiéndolos de solemnidad y formas legales.

La labor del Notario Público, impuesta por el Estado, es ejercida de manera imparcial e independiente. Sus actividades no sólo se limitan a dar fe y legalidad de los actos, sino que brinda seguridad jurídica a las partes, evita los posibles litigios y conflictos que pueden surgir ante cualquier eventualidad entre las partes derivado de su capacidad para ejercer la mediación jurídica.

Francisco Martínez Segovia (Nicolás, 1992) expuso que la función notaria es compleja, compuesta de acciones y ejercicios profesionales y documentales indivisibles. Este dualismo tiene como finalidad el proveer a la seguridad, valor y permanencia, de hecho y de derecho al documento notarial y a su objeto o contenido. Estos fines se fusionan entre sí de manera indiscutible y para alcanzarlos, se sirve del notario y su pericia jurídica, además del documento notarial.
El Notario Público es un jurista que realiza acciones de función autónoma y de carácter privado, pero con efectos públicos y legales (pues su función nace de la existencia de la ley).

En México, el deber del notario es asesorar a las partes, interpretando su voluntad, tiene el deber de redactar, leer, explicar y autorizar el instrumento correspondiente, así como conservarlo y reproducirlo. El notario interviene en diversos actos como lo son: testamentos, poderes, constitución de sociedades y asociaciones, así como de aquellos cuyo objeto sean inmuebles, por ejemplo, en compraventas, donaciones, hipotecas, fideicomisos y adjudicaciones por herencia. Además, realiza fe de hechos, notificaciones, requerimientos, existencia y capacidad de las personas, reconocimiento de firmas, protocolizaciones de actas y hechos materiales en general.

El Colegio de Notarios del Distrito Federal (1988) menciona en sus estatutos entre otras cosas que el notario público tendrá facultades como: aceptar y desempeñar cargos académicos y docentes, ser tutor, curador y albacea, ser árbitro o secretario en juicio arbitral, ser mediador jurídico, ser conciliador, patrocinar a los interesados en los 
Periódico do Núcleo de Estudos e Pesquisas sobre Gênero e Direito

Centro de Ciências Jurídicas - Universidade Federal da Paraíba

V. 9 - $\mathrm{N}^{\circ} 01$ - Ano 2020 - Spanish Edition

ISSN | 2179-7137 | http://periodicos.ufpb.br/ojs2/index.php/ged/index procedimientos judiciales o

administrativos necesarios para obtener

el registro de escrituras; y semejantes

que no causen conflicto ni dependencia

que afecte su dación de fe y asesoría imparcial.

La función del notario consiste en dar forma, probar y brindar eficacia a un acto. Además, por medio de la fe pública le da firmeza al documento notarial.

\section{El matrimonio}

El matrimonio es considerado un acto solemne que se realiza entre un hombre y una mujer de manera voluntaria, ante una persona autorizada por el Estado, con el propósito de establecer una comunidad de vida entre ellos y una convivencia permanente (Baqueiro Rojas, 1997).

$$
\text { En este acto hay ritos } \mathrm{y}
$$
formalidades legales que brindan certeza sobre la voluntad de las partes que deciden unir sus vidas. Derivado del matrimonio surge el concepto de familia concebido como el grupo de personas ligadas directamente por el parentesco, cuyos integrantes asumen la responsabilidad del cuidado de los hijos, además de que la familia, antes de ser un concepto jurídico es sociológico

\section{6}

(Carbonell, 2006) pues sus efectos se extienden a determinados grados, reconocidos por los mismos integrantes. En línea recta no existen límites para establecer un parentesco; sin embargo, en línea colateral, los efectos de éste se extienden hasta el cuarto grado, aunque la ley civil establezca límites y los integrantes de una familia los extiendan más allá de estos.

Desde el punto de vista teleológico, el matrimonio es una sociedad física y espiritual, excluyente e indisoluble, en la que se requiere el consentimiento del varón y de la mujer y de la que derivan las relaciones de parentesco. La finalidad es la de procrear y educar a la descendencia. Santo Tomás consideraba que la unión matrimonial era indiscutible y marital entre personas legítimas que observaban una invisible comunidad de vida (Barros Álvarez, 2001). Ulpiano acepta que el matrimonio representaba la unión entre hombre y mujer, que se unían bajo una comunión habitual e indivisible de vida (Abundis Rosales \& Ortega Solís, 2010).

El Código Napoleónico retoma la idea naturalista de que el hombre y la mujer se unen con la finalidad de perpetuar la especie, para socorrerse y asistirse mutuamente y para sobrellevar 
el peso de la vida bajo un destino en común (Hernández, 2012).

Existen dos elementos indispensables para que se establezca la figura del matrimonio: la voluntad de las partes que, sin coacción alguna, violencia, dolo o mala fe, quieren formar una familia; y el de crear un estado de permanente vida entre la pareja, compartiendo deberes, derechos $\mathrm{y}$ obligaciones en común con el objetivo de proteger los intereses colectivos de la familia, como lo son la procreación, la alimentación, la educación y la protección de los hijos (Galindo, 1989).

En este aspecto, hay que separar al matrimonio que se realiza por la vía civil, del religioso. En éste último, ésta figura es considerada un sacramento de naturaleza indisoluble, que celebran las partes entre sí, por su libre y espontánea voluntad, de duración continua y que cesa con la muerte de alguno de los contrayentes. Durante mucho tiempo se consideró por parte de la iglesia católica que el matrimonio se establecía en función de la maternidad.

En algunos casos, la sociedad considera al matrimonio religioso como un mandato divino celebrado entre un hombre y una mujer con la finalidad de procrear y multiplicarse pues este fue un mandato del creador desde el inicio de la humanidad.

El Sacramento del matrimonio, desde el punto de vista religioso es considerado una íntima comunión de la vida y del amor conyugal, creada por Dios, el cual es regido bajo las leyes para que se establezcan sobre la alianza de los cónyuges". De esta manera para la iglesia, el matrimonio es una unión duradera o hasta que la muerte separe a las partes, lo que le da validez a la institución y constituye una garantía social.

El cristianismo centra los orígenes del matrimonio en la propia voluntad del creador y está inscrito en la naturaleza misma del hombre y la mujer como objeto mismo de la capacidad creativa de ese ser superior. El matrimonio es visto también como la salvación de la persona, de la sociedad humana y cristiana, principalmente porque está ligada a la prosperidad de la comunidad conyugal y familiar (Catholic Church, 2005).

\section{¿El matrimonio es un contrato?}

Existen todavía teóricos que dudan de la naturaleza del matrimonio. Algunos consideran que es un contrato ya que en el mismo se establece la 
voluntad de las partes para generar derechos y obligaciones.

En el caso del matrimonio, al celebrarse este acto en presencia de un oficial del registro civil, el acta de matrimonio cuenta con los tres elementos de existencia básicos: voluntad, objeto y solemnidad; aunado a elementos que lo hacen valido como la formalidad, la ausencia de vicios pues el dolo, el error o la violencia lo pueden invalidad; la capacidad de ejercicio de las partes, ya que la ley exige que se realice a partir de los dieciocho años, que es la edad legal para considerarse sujeto de derechos y obligaciones contractuales; además de que debe ser lícito; es decir, las partes no haber contraído matrimonio previamente, sino se estará en presencia de la figura jurídico de bigamia, la cual es sancionada por las leyes penales.

Los detractores de esta teoría son acordes en señalar que, si bien es cierto, el matrimonio cuenta con los elementos indispensables para ser considerado un contrato, carece de un objeto desde el punto de vista jurídico, además de que la cosa o derecho no se encuentra dentro del comercio; y por la entrega recíproca de los cónyuges.
48

En ese sentido, las categorías contractuales parten del ámbito de lo patrimonial y no de lo personal; asimismo, otro elemento es la justificación dela indisolubilidad del matrimonio. Esto último ha dado lugar a diversos argumentos. Hay una gran cantidad de contratos que por ser de cumplimiento o de ejecución única e instantánea, no se puede afirmar que sean disolubles o indisolubles, porque cuando el acto se consuma, no hay ni rescisión ni revocación posible. Sin embargo, no se puede perder de vista que existen características que lo hacen diferente a cualquier otro tipo de acción contractual; en el matrimonio, una de las obligaciones que tienen los cónyuges es el débito conyugal, mismo que viene aparejado con la relación obligatoria de recíprocas prestaciones genitalesprocreativas (Vázquez García-Peñuela, 1999).

Además, una de las características del matrimonio es la estabilidad o la permanencia de la unión no sólo para que los esposos hagan una vida en pareja, sino para la procreación, manutención y educación de los hijos.

En el caso de los contratos, el Estado no interviene y los acuerdos quedan al libre arbitrio de las partes; 
empero, en el matrimonio existen derechos y obligaciones no sólo para los cónyuges sino para la familia. En este sentido, el Estado reglamenta, regula y protege esta institución a través de los oficiales del Registro Civil quienes otorgan la validez al acto. Al respecto, una vez celebrado el acto, el acuerdo de voluntades de las partes fija los derechos y obligaciones de cada una de ellas que, por cierto, ya están establecidos dentro de la ley y los consortes solo son libres para escoger el régimen matrimonial bajo el que establecerán la sociedad conyugal.

Sin embargo, no se puede perder de vista que el matrimonio sólo es válido si se realiza con las formalidades que establece la ley y ante una autoridad investida para ello.

El problema del matrimonio radica en la temporalidad propia de cada contrato y su regulación y tratamiento cambia de acuerdo a la época y a los intereses sociales y políticos. Desafortunadamente la naturaleza contractual del contrato está ligada a la teleológica. El matrimonio es el acto mediante el cual el hombre y la mujer disponen de su propia vida, relacionándose con una sólida institución en la que el consentimiento de los contrayentes, el amor, la perpetuidad y la continuidad de la descendencia eran los ejes rectores; empero, con el paso del tiempo, estos argumentos se han venido debilitando dándosele preferencia a la voluntad de las partes que deciden constituirse en cónyuges, sin coacción alguna. En Colombia se reconoce que el matrimonio trae consigo otras responsabilidades como es el establecimiento de una sociedad conyugal sólida, con la obligación de socorro y ayuda mutua, además de buscarse una estabilidad social, económica, política y emocional (Rojas Araque, 2011).

El matrimonio ha sido considerado desde distintos puntos de vista:

a). - Como Institución se dice que la constituye debido a los diferentes preceptos que regulan, tanto el acto de su celebración al establecer elementos esenciales y de validez, como las que fijan los derechos y obligaciones de los consortes, pues persiguen la misma finalidad al crear un estado permanente de vida, que será la fuente de una gran variedad de relaciones jurídicas.

b). - Como contrato ordinario desde que se separó al matrimonio civil del religioso, pues tanto el derecho 
positivo como la doctrina consideran que este contrato cuenta con todos los elementos esenciales y de validez de este acto jurídico. Para su celebración, es necesario que los contrayentes expresen su consentimiento, como una forma de manifestación de voluntades y para que no deje lugar a cuál era el deseo de los participantes. Es importante señalar que, en el matrimonio celebrado ante un oficial del registro civil, -por manifestación expresa de la ley- se deben observar todas las reglas para la validez de los contratos, además de que los contratantes sean mayores de edad, para evitar que sobrevenga una causa de nulidad.

c). - Como Estado Jurídico, el matrimonio produce situaciones jurídicas permanentes. Éste constituye un estado jurídico entre los consortes, pues con la voluntad de estos se crea una situación jurídica permanente, que origina consecuencias jurídicas constantes, durante toda la vida matrimonial

d). - Como acto de poder estatal, para la realización del matrimonio, es necesario que éste se realice por autoridades facultadas por el Estado.

En la actualidad es importante mencionar, que el concepto de matrimonio ha variado, aunque en algunos lugares, los Códigos Civiles no han sido modificados y no reconocen de manera expresa el matrimonio igualitario o la unión de personas del mismo sexo. Originalmente era un contrato que se celebraba ante el oficial del Registro Civil en la Ciudad de México (único lugar que legisló en la materia) y en el que se reconocían derechos y obligaciones de las parejas. En el acuerdo que celebraban las partes, expresaban su voluntad para fijar una sociedad de convivencia. A través de esta figura, el grupo LGBT logró que se les permitirá regularizar su unión, aunque aún en otros lados, ésta sociedad no se equipara al casamiento.

\section{Efectos del matrimonio}

De acuerdo al Código Civil para el Distrito Federal (2019), el matrimonio es la unión libre de dos personas para realizar la comunidad de vida, en donde ambos se procuran respeto, igualdad y ayuda mutua. Debe celebrarse ante el Juez del Registro Civil, con las formalidades que estipule la ley. Por ello, para que el matrimonio sea válido, éste debe realizarse en una institución pública de interés social, a través de la cual se inscriba, autorice, certifique y de 
publicidad a los hechos y actos que se constituyan o modifiquen el estado civil de las personas.

En México, los encargados de darle validez a los actos relacionados con el estado civil de las personas reciben el nombre de oficiales del registro civil (CGAJ, 2019), quienes cuentan con fe pública para el desempeño de sus labores y a ellos les corresponde el asentamiento de las actas de nacimiento, reconocimiento de hijos, adopción, matrimonio, divorcio administrativo, defunción e inscripción de sentencias ejecutoriadas en las que se declare la dispensa del juez para contraer matrimonio, la presunción de muerte, la tutela, y la pérdida o limitación de la capacidad legal para administrar bienes. Este documento tiene valor probatorio pleno y sirve para acreditar o demostrar el estado civil de las personas.

Quienes pretendan contraer matrimonio deberán presentar una solicitud por escrito y firmada, ante el Oficial del Registro Civil del domicilio de cualquiera de ellas, en la que se expresará, de forma enunciativa: el nombre, la edad, la ocupación y el domicilio de los solicitantes, así como el nombre de sus padres; que no tienen impedimento para contraer nupcias y, que es su voluntad unirse en una sociedad de convivencia, precisando el régimen económico bajo el cual se unirán. El Código Civil de Tabasco es específico en señalar que el matrimonio debe celebrarse ante los funcionarios que establece la ley y con las solemnidades que ella exige.

Cuando una persona contrae matrimonio, hacen la promesa de amarse y respetarse. La ley señala que los esposos deben guardarse fidelidad, vivir juntos en un domicilio conyugal, contribuir a los fines del matrimonio y brindarse ayuda mutua; esto sin dejar de lado a los hijos. La Constitución Política Mexicana (Diputados, 2019) indica como derecho para las personas, el decidir sobre el número de los hijos y el espaciamiento entre éstos; además de poder emplear cualquier método de reproducción artificiar para lograr la descendencia, siempre y cuando ambos estén de acuerdo.

En ese mismo sentido, a partir de que el Estado hace el reconocimiento de la unión realizada ante el Oficial del Registro Civil a través de la publicidad que se le dará al evento, la sociedad brinda su aceptación hacia la nueva unión, aceptándolo como una nueva 
célula y posible formadora de una nueva familia.

Entre consortes, los efectos de la celebración del matrimonio se integran por el conjunto de derechos y deberes irrenunciables, permanentes, recíprocos, de contenido ético-jurídico: fidelidad, cohabitación y asistencia. Con relación a los hijos, se le atribuye la calidad de hijos habidos en matrimonio. En caso de que hubieran nacido hijos fuera del matrimonio, el enlace matrimonial los legitima. Con respecto a los bienes, la ley regula las donaciones antenupciales y entre consortes.

\section{Los alimentos}

Dentro del matrimonio surge la obligación de proporcionarse alimentos por partes iguales; compromiso que se extiende también a los hijos. En el caso de los cónyuges, los alimentos pueden repartirse en proporción distinta, de acuerdo a los ingresos que cada uno tenga. La ley protege a la mujer que se ha dedicado a las labores del hogar y al cuidado y crianza de los hijos. En caso de una separación, la ley establece que ella tiene derecho a una pensión alimenticia. Misma suerte sufre el cónyuge que carezca de bienes propios o esté imposibilitado para trabajar.
La Suprema Corte de Justicia de la Nación (SCJN, 2019) ha dicho en el caso de los alimentos que, para que exista un derecho a recibirlos, así como la obligación de otorgarlos, debe existir un vínculo jurídico o una relación jurídica como el matrimonio, concubinato o parentesco, ya sea consanguíneo o civil. Principalmente porque de la unión voluntaria de las personas surgió un compromiso y esto surge del acuerdo de ambas partes. Sin embargo, en muchos de los casos, el matrimonio se acredita con el acta de matrimonio respectiva, pero para el concubinato es una situación más complicada.

En el caso de los menores, el acto de reconocimiento (certificación del nacimiento) coloca en un estado de protección a los hijos y esta obligación la de proporcionar alimentos- se extiende a aquellos familiares más próximos en grado en caso de que los padres no puedan cumplir con esta responsabilidad. La Ley señala que a falta o imposibilidad de los progenitores o de los hijos e hijas, la obligación recae en los demás ascendientes por ambas líneas que estuviera más próximo en grado. Si éstos tampoco pueden, entonces serán los hermanos o hermanas 
del padre y la madre quienes subsanarán esta deficiencia.

Los alimentos son concebidos como la asistencia que se le da a algunas personas para su manutención y subsistencia, es decir, para comida, bebida, vivienda, salud y educación cuando el acreedor alimentario es menor de edad o está incapacitado para procurarlos; por eso, también es considerado como el derecho que tiene una persona de recibir los recursos necesarios para su subsistencia, por parte de un obligado, ya sea porque existe un mandamiento legal que así lo establece o bien por convenio o sentencia judicial.

Rojina Villegas (2004) ha señalado que, los alimentos tienen las siguientes características: a) son recíprocos; b) son personalísimos; c) son intransferibles; d) inembargables; e) son imprescriptibles; f) intransigibles; g) proporcionales; h) divisibles; i) preferentes, j) no compensables ni renunciables, y k) no se extinguen en un solo acto; de ahí su reciprocidad.

\section{Regímenes económicos}

Cuando la pareja decide establecer una relación afectiva y capitalizarla a través del matrimonio, al momento de celebrar el evento ante el oficial del registro civil, deben indicar bajo qué régimen fijarán la sociedad conyugal. En otras palabras, pueden optar por un régimen de separación de bienes o por el de sociedad conyugal. Ante la omisión de elegir alguno, se les tiene casados bajo el régimen de sociedad conyugal.

La sociedad conyugal o bienes mancomunados es la unión de los bienes maritales que se obtengan después de celebrado el matrimonio, y en ella no participan los bienes que integraban el patrimonio de cada uno de los consortes antes de celebrarse el acto de matrimonio. A partir del momento de la unión conyugal, cuando uno de los cónyuges adquiera un bien, aun cuando no haya firmado el otro, la propiedad pertenece a ambos; es decir, cada uno tendrá derecho al 50\% del mismo.

La sociedad conyugal debe concebirse como una persona jurídica, con patrimonio propio, tanto de bienes presentes como futuros, administrados por un representante que puede ejecutar actos de dominio y administración general (Rojina Villegas, 1981) a partir de la celebración del matrimonio y que termina con la disolución del matrimonio o antes de ésta, por convenio de los cónyuges o por resolución judicial. En 
otras palabras, cuando sobreviene la separación, todo se divide en partes iguales (CGAJ, 2019).

El régimen de sociedad conyugal consiste en la formación y administración de un patrimonio común, diferente del patrimonio propio de cada uno de los consortes. Es importante señalar que, las partes pueden cambiar de régimen matrimonial después de celebrado el matrimonio

Caso contrario es el régimen de separación de bienes, en el cual los bienes que cada cónyuge adquiere durante el matrimonio es de cada uno de ellos, sin que la otra parte tenga derecho a alguna parte, salvo que uno de ellos fallezca y lo establezca en una herencia. En este caso, cada uno de los cónyuges conserva la administración y propiedad de sus bienes, bien sea los previos o los que adquiera durante el matrimonio.

$\mathrm{Al}$ respecto, y para determinar la propiedad de cada una de las partes con respecto a los bienes que tienen previo al matrimonio o durante el mismo, la ley hace referencia a la existencia de las capitulaciones matrimoniales que se consideran un acuerdo de voluntades de los cónyuges en virtud del cual se establece la modificación o sustitución del régimen económico del matrimonio.

Las capitulaciones son pactos entre los otorgantes que celebran para establecer y regular el régimen patrimonial del matrimonio. Estas se establecen de manera preferente previo al enlace, durante el matrimonio, ante la autoridad competente, que sería un juez de lo familiar o bien un notario, quien elaborará una escritura pública (Pérez Contreras, 2010).

Las capitulaciones se definen como los pacto hechos entre los otorgantes que celebran para constituir un régimen patrimonial de su matrimonio y reglamentar la administración de los bienes, la cual recaerá en ambos cónyuges, salvo pacto en contrario. La labor de autorización o de dar fe con respecto a la constitución y modificación voluntaria de capitulaciones le corresponde al notario público.

Se considera que las capitulaciones matrimoniales son un requisito previo a la celebración de los esponsales; sin embargo, en la realidad las parejas son omisas en este sentido y para ellos basta indicar al oficial del registro civil que quieren casarse bajo el régimen de separación de bienes para 
que sea anotado en el acta de matrimonio (Contreras Bustamante, 2012).

A esto se agrega que los representantes del Estado están saturados de trabajo y difícilmente puedan dialogar con las partes $\mathrm{y}$ explicarles el alcance de las capitulaciones y sólo se limitan a recabar los formatos y ver que los cónyuges reúnan los requisitos. Esto da lugar a múltiples interpretaciones porque anteriormente el Código Civil del Distrito Federal establecía que mientras no se aprobara que los bienes y utilidades obtenidos por alguno de los cónyuges pertenecen a sólo uno de ellos, se presume que forman parte de la sociedad conyugal.

\section{El contrato en el matrimonio}

Se debe reconocer que el contrato matrimonial ha dejado de ser una práctica usual en México, país lleno de extensa cultura, tradiciones y creencias, entre ellas, que es el varón quien provee y la mujer tiene un rol doméstico. A pesar de que los patrones de género han evolucionado, aún en algunas regiones se sexualiza el trabajo tanto del hombre como de la mujer. En ese mismo sentido, las parejas han optado por la unión libre como medio
55

para crear una familia; eso sí, con amplios beneficios para el varón.

A pesar de la diferencia ideológica entre generaciones y con la intención de desaparecer roles definidos durante la evolución histórica del país, convivir bajo el régimen de sociedad conyugal ha sido lo habitual, incluso se tiene la creencia que, si la pareja realmente ama a la otra parte, tienen que compartir todo, incluso sus bienes y casarse bajo este régimen; mientras que otorgar capitulaciones para la separación de bienes ha sido una fórmula a la que sólo recurrían famosos, influyentes o personas obscenamente adineradas, incluso se creía que aquellos quienes no estaban seguros de su compromiso a largo plazo, optaban por este régimen ante el temor de tener que dividir sus bienes.

Sin embargo, aunque hoy siguen siendo minoría las parejas que se plantean que antes o después del matrimonio pueden suscribir un contrato en el que establezcan voluntariamente el régimen económico por el que se va a regular su unión, se observa un incremento de esta práctica, haciéndola cada vez más común.

Lo habitual es que el contrato matrimonial se utilice para otorgar 
capitulaciones, empero, se trata de un acuerdo que se realiza ante notario público, que se menciona en la inscripción del matrimonio en el Registro Civil, sin más limitaciones que las que establece la norma, determinando que el contrato matrimonial como tal, no puede vulnerar nunca la igualdad de derechos que corresponde a cada cónyuge; es decir ninguno puede sustraerse a esta norma, por lo tanto, en un contrato de este tipo se acopla al ámbito estrictamente material y recoge los bienes que cada uno aporta al matrimonio; establece las condiciones de vida del matrimonio en conjunto así como la estabilidad económica, si existe alguna norma que permite que los cónyuges celebren entre sí, contratos para transmitirse bienes.

\section{A manera de conclusión}

Se debe reconocer que el tema puede ser extenso; sin embargo, el matrimonio ante notario permite garantizar a la pareja la validez de un acto. El matrimonio es ya de por sí un contrato legal, aunque sea sui generis por sus propias características, pero genera una serie de efectos de carácter personal, patrimonial y económico. Sin embargo, firmar ante notario las capitulaciones matrimoniales, permite regular la parte monetaria de la unión.

El notario público tiene fe pública, lo que se considera una garantía pues esta le permite establecer una presunción legal de la verdad (Giménez Arnau, 1976), o bien un imperativo jurídico impuesto por el Estado vigente mientras no se demuestre que es un acto falso. El Notario es el responsable de interpretar la voluntad de las partes y plasmarla en un documento público y auténtico. Al contar el notario con fe pública permite dar publicidad a los actos, además de que las personas adquieren certeza, validez y eficacia, aunado a que no se necesita de prueba.

Por ello, siguiente los ejemplos de otros países, la figura del notario para la consecución del matrimonio disminuiría los trámites que tienen que realizarse ante el oficial del registro civil, además de que, los requisitos podrían ser menos restrictivos que ante los órganos del Estado, como es el caso de la comunidad LGBT que, cuando acude a las instancias estatales, su petición de matrimonio es rechazada bajo el argumento de que las uniones de derecho de las parejas perteneciente a este grupo, no están reguladas. De ahí la necesidad de que sea un notario público el que dé 
Periódico do Núcleo de Estudos e Pesquisas sobre Gênero e Direito Centro de Ciências Jurídicas - Universidade Federal da Paraíba V. 9 - $\mathrm{N}^{\circ} 01$ - Ano 2020 - Spanish Edition ISSN | 2179-7137 | http://periodicos.ufpb.br/ojs2/index.php/ged/index cumplimiento a lo establecido en la ley para el caso del matrimonio, sin afectar la voluntad de las partes $y$ al ser conocedor del derecho, le brindará mayor certeza y una mejor orientación para las partes.

\section{Bibliografia}

Abundis Rosales, M. A., \& Ortega Solís, M. Á. (2010). Matrimonio y divorcio: antecedentes históricos y evolución legislativa. México: Universidad de Guadalajara.

Bañuelos Sánchez, F. (1976). Derecho Notarial. México: Cárdenas.

Baqueiro Rojas, E. (1997). Derecho de familia y Sucesiones. México: Harla.

Barros Álvarez, V. A. (2001). El matrimonio en el mundo actual. Chile: Universidad de Chile.

Carbonell, M. (2006). Familia, Constitución y Derechos Fundamentales. En R. M. Álvarez de Lara, Panorama Internacional de Derecho de Familia, Cultura y Sistemas Jurídicos Comparados, Tomo I (págs. 81-82). México: UNAM.
Catholic Church. (2005). Compendio de la doctrina social de la iglesia. Lima: Paulinas.

CGAJ. (16 de Octubre de 2019). Código Civil para el Estado de Tabasco. Obtenido de Coordinación General de Asuntos Jurídicos del Gobierno del Estado de Tabasco: https://tabasco.gob.mx/leyes/descargar/ 0/302

Colegio de Notarios del Distrito Federal. (1988). Estatutos del Colegio de Notarios del Distrito Federal. Revista de Derecho Notarial Mexicano núm 97, 136-148. Obtenido de Colegio de Notarios Ciudad de México.

Contreras Bustamante, R. (2012). La importancia de las capitulaciones matrimoniales en la nueva realidad social de México. En J. A. Domínguez Martínez, \& J. A. Sánchez Barroro, Conmemoración de los 80 años de vigencia del Código Civil (págs. 53-70). México: UNAM/ Colegio de Profesores de Derecho Civil. 
Periódico do Núcleo de Estudos e Pesquisas sobre Gênero e Direito Centro de Ciências Jurídicas - Universidade Federal da Paraíba V. 9 - $\mathrm{N}^{\circ} 01$ - Ano 2020 - Spanish Edition ISSN | 2179-7137 | http://periodicos.ufpb.br/ojs2/index.php/ged/index

Diputados. (2019). Código Civil

Federal. México: Cámara de Diputados

del H. Congreso de la Unión.

Pérez Fernández del Castillo, B. (1983).

Derecho Notarial. México: Porrúa.

Diputados. (2019). Constitución Política

de los Estados Unidos Mexicanos.

México: Cámara de Diputados del H.

Congreso de la Unión. Secretaría

GEneral. Secretaría de Servicios

Parlamentarios.

Galindo, I. (1989). Derecho Civil Primer

Curso. Parte general, Personas y

Familia. México: Porrúa.

Giménez Arnau, E. (1976). Derecho Notarial. Madrid: Eunsa.

Rojas Araque, D. A. (2011).

Caracterización del matrimonio ¿Es un contrato? Nuevo Derecho, Vol. 7 No. 9, 25-37.

Rojina Villegas, R. (1981). Derecho

Civil Mexicano, bienes y derechos reales y posesión. México: Porrúa.

Rojina Villegas, R. (2004). Compendio de Derecho Civil. Introducción, Personas y Familia. México: Porrúa.

SCJN. (2019). Alimentos. Fundamento u

Hernández, L. (2012). El matrimonio.

Obtenido de Temas de Derecho: https://temasdederecho.wordpress.com/t ag/evolucion-historica-del-matrimonio/

Nicolás, G. C. (1992). Manual del

Derecho Notarial. Buenos Aires: Ediciones De Palma. origen del derecho y la obligación entre los cónyuges de proporcionarlos. En S. C., Semanario Judicial de la Federación, Décima Época (pág. 742). México: Suprema Corte de Justicia de la Nación.

Vázquez García-Peñuela, J. M. (1999).

El matrimonio es un contrato (concretamente un contrato de sociedad).

Pérez Contreras, M. d. (2010). Derecho Ius Canonicum, 611-618.

de familia y sucesiones. México:

UNAM. 
Periódico do Núcleo de Estudos e Pesquisas sobre Gênero e Direito Centro de Ciências Jurídicas - Universidade Federal da Paraíba V. 9 - $\mathrm{N}^{\circ} 01$ - Ano 2020 - Spanish Edition ISSN | 2179-7137 | http://periodicos.ufpb.br/ojs2/index.php/ged/index

Zejalbo Martín, J. (7 de junio de 2012).

El matrimonio ante notario:

antecedentes históricos de una realidad

actual. Obtenido de Notarios y

Registradores:

https://www.notariosyregistradores.com

/doctrina/ARTICULOS/2012-

matrimonio-ante-notario.htm 